\title{
URGENT PROBLEMS OF TEACHING METHODS OF SCIENTIFIC RESEARCH TO POSTGRADUATE STUDENTS-LINGUISTS
}

(C) 2020

\author{
Stoikovich Galina Vladimirovna, candidate of philological sciences, \\ professor of the English Philology and Cross-cultural Communication Department \\ Samara State University of Social Sciences and Education (Samara, Russian Federation) \\ Stoikovich Liliya Yuryevna, candidate of philological sciences, \\ associate professor of Linguistics and Foreign Language Business Communication Department \\ Samara State University of Economics (Samara, Russian Federation)
}

\begin{abstract}
The paper is devoted to the description of the organization and content of the teaching process at the Foreign Language Department, SSUSSE, concerning postgraduate students of Linguistics, namely, the experience of teaching them research activities and methods of fulfilling them. In addition, the authors rely on the experience of prominent scientists and specialists in this sphere. Scientific research activity is one the most important components in masters' training, as its goal is the development of certain competences, reflected in their graduation qualification paper (master's thesis). The authors present the stages of scientific research work, including the introduction into the methodology of linguistic research, research practices, writing course papers, master's thesis, reports for conferences; they note how it is important to use methods of linguistic analysis to make the research valid. The paper characterizes and substantiates both general and specific scientific methods used for research in the sphere of translation and cross-cultural communication (comparative, descriptive, component, discourse analysis, content analysis and others), which are illustrated by the examples of their use in students' research papers. The authors' conception is based on the official standards and authoritative sources in the spheres of linguistics, lingua-didactics, and translation study.

Keywords: teaching process; masters' training; research methods; research activities; master's thesis; competences; linguistic analysis; translation; intercultural communication; comparative method; descriptive method; component; content analysis; translation study; lingua-didactics.
\end{abstract}

$* * *$

УДК $37,372.881$

DOI $10.24411 / 2309-4370-2020-11312$

Статья поступила в редакцию 21.12.2019

\section{УЧЕТ КОГНИТИВНО-ПСИХОЛОГИЧЕСКИХ ХАРАКТЕРИСТИК КИТАЙСКИХ УЧАЩИХСЯ ПРИ ОБУЧЕНИИ РУССКОЙ ГРАММАТИКЕ}

(C) 2020

Сунь Юй, аспирант кафедры русского языка как иностранного и методики его преподавания

Санкт-Петербургский государственный университет (2. Санкт-Петербург, Российская Федерация)

Аннотация. В статье рассматривается проблема национально-ориентированного обучения китайских студентов русскому языку. Автор анализирует работы, которые посвящены исследованию когнитивно-психологических особенностей носителей китайской культуры. В результате анализа выявлены специфические учебные стратегии, которыми пользуются китайские учащиеся при изучении иностранного языка. При обучении мононациональной группы оптимальным считается национально-ориентированный подход. Для реализации этого подхода необходим сравнительный анализ систем контактирующих языков, чтобы определить зоны межъязыковой и внутриязыковой интерференции. Важнейшим фактором эффективности учебного процесса является адекватность представлений преподавателей о студентах различных регионов. Автор приходит к выводу, что в целях поддержания мотивации к овладению русским языком и оптимизации процесса обучения при разработке учебных программ и пособий, ориентированных на китайских студентов, необходимо стремиться сделать процесс обучения не только результативным, но и максимально комфортным для обучающихся. Учет когнитивно-психологических характеристик китайских учащихся не только будет способствовать формированию прочных грамматических навыков, но и обеспечит развитие устно-речевых умений на русском языке. В статье даются рекомендации для интенсификации процесса обучения китайских студентов русской грамматике. Использованы следующие методы исследования: сравнительно-сопоставительный анализ; анализ и синтез.

Ключевые слова: иноязычная речевая деятельность; обучение; грамматика; этнокультурный аспект; когнитивно-психологические характеристики; грамматический навык; грамматические упражнения; способы подачи грамматического материала; русский язык как иностранный (РКИ); китайские учащиеся.

\section{Постановка проблемы}

С расширением китайско-российских культурных связей все больше китайских студентов выбирают русский язык в качестве иностранного языка. Практика показывает, что китайские студенты, приступающие к изучению русского языка, испытывают определенные трудности, особенно при усвоении грамСамарский научный вестник. 2020. Т. 9, № 1 (30) матической системы. Недостаточный уровень сформированности грамматических навыков у данного контингента учащихся тормозит процесс развития устно-речевых умений. К сожалению, большинство китайских студентов не способны успешно применять имеющиеся у них знания, навыки и умения в реальной коммуникации на русском языке. Посколь- 
ку китайские учащиеся чаще всего предпочитают работать с образцами, то наблюдается слабая активность и инициативность на занятиях по грамматике русского языка. На наш взгляд, такое положение дел в значительной степени обусловлено отсутствием учета когнитивно-психологических характеристик китайских студентов в практике преподавания русского языка как иностранного (РКИ).

Известно, что грамматика, будучи абстрагированным уровнем языковой системы, тем не менее является основой для оформления речевого высказывания. Изучая иностранный язык, учащийся овладевает действиями и операциями с языковым материалом для правильного конструирования высказываний, понимания иноязычной речи, а также сознательного контроля построения высказываний и выбора требуемых грамматических форм и конструкций [1].

Не вызывает сомнения утверждение, что результативность общения на неродном языке во многом зависит от знаний и уровня владения навыками использования языковых средств в речи. С точки зрения И.А. Зимней, для реализации замысла в соответствии с коммуникативным намерением важно, чтобы говорящий знал «средства и способы выражения мысли на данном языке; он должен обязательно уметь пользоваться этим знанием по ходу выражения мысли» [2, с. 173]. В связи с этим работа по формированию и закреплению грамматических навыков как компонентов речевого умения имеет первостепенное значение, особенно на начальном этапе обучения. Согласно А.А. Леонтьеву, обучение иноязычной речевой деятельности осуществляется с учетом навыков речевого общения на родном языке [3, c. 297]. Другими словами, иностранный учащийся овладевает грамматическими навыками на изучаемом языке, располагая уже сложившейся системой родного языка.

При обучении мононациональной группы оптимальным считается национально-ориентированный подход, при котором учебный процесс строится на основе данных сравнительно-сопоставительного анализа систем контактирующих языков, благодаря которому выявляются наиболее трудные для усвоения грамматические явления, очерчиваются зоны межъязыковой и внутриязыковой интерференции, прогнозируются типичные ошибки. Таким образом, происходит формирование грамматического навыка «с коррекцией» (термин А.А. Леонтьева).

Следует иметь в виду, что при обучении иностранному языку происходит не только «столкновение» разных языковых систем, но и «"встреча" двух типов вербального мышления, двух типов культур со своеобразной интерпретацией окружающей действительности, где мир рассматривается через призму особого (своего) мировидения и кодируется средствами различных языковых систем [4, с. 4]. Результатом этой "встречи" является формирование новой языковой компетенции на базе уже имеющихся (специфичных для родного языка) речевых навыков и когнитивно-психологических особенностей обучающегося. Поэтому для эффективного обучения грамматическому аспекту иностранного языка недостаточно сопоставления родного и изучаемого языков, в большинстве случаев "требуется разработка психолингвистической модели", учитывающей степень совпадения или расхождения операционной структуры речевой деятельности двух языков» [3, с. 297-299].
Цель данной статьи: выявление и систематизация этнокультурных и когнитивно-психологических характеристик китайских студентов; анализ методики преподавания русского языка китайским учащимся и разработка этнометодических рекомендаций при обучении данного национального контингента русской грамматике, которые способствовали бы оптимизации учебного процесса и мотивировали к дальнейшему овладению русским языком как иностранным (РКИ).

\section{Обзор литературы}

Анализ научно-методической литературы свидетельствует о том, что даже при коммуникативной направленности обучения иностранному языку главной трудностью для овладения грамматическим строем неродного языка остается использование грамматических моделей в речи и участие в реальном общении, где коммуникация осложняется наличием не только языкового, но и психологического барьеров. Это замечание особенно актуально для студентов из тех стран, где традиционно используется некоммуникативный стиль преподавания, например - для китайцев.

Как отмечают многие исследователи, выход в реальное общение до сих пор является самой острой проблемой при обучении китайцев русской грамматике: если студент даже «удовлетворительно усвоил грамматическую модель на уроке, он не может использовать ее в речи» [5, с. 162]; «перевод полученных грамматических знаний в живую разговорную речь - довольно трудный процесс <...>, так как китайские учащиеся мало общаются по-русски» [6]; большинство китайских учащихся «с трудом овладевают речевыми навыками, с трудом преодолевают психологический барьер в процессе коммуникации» [7, с. 21].

Многие авторы, исследующие этнометодические аспекты обучения китайских учащихся русскому языку, одной из главных причин низкого уровня владения РКИ называют несоответствие между технологиями, применяемыми в российских вузах, и менталитетом учащихся из восточных стран [8].

Е.Ю. Кошелева, И.Я. Пак и Э. Чернобыльски отмечают, что китайская модель обучения складывается из двух базовых компонентов:

- конфуцианские принципы коллективистского общества (уверенность в том, что усердие может компенсировать недостаток способностей; отношение к учителю как к образцу для подражания и носителю неоспоримых знаний; трудолюбие в учебе);

- особенности образовательной системы Китая (обучение центрировано на учебнике и предполагает процесс аккумулирования знаний; смысл преподавания заключается лишь в передаче безоговорочных знаний от учителя к ученику, поэтому китайцы больше склонны слушать преподавателя, чем возражать ему или вступать в дискуссию, вследствие чего они боятся сделать ошибку и почти не выражают стремления к речевой инициативности; нацеленность обучения на сдачу письменных тестов, поэтому главное - это хорошая память, а не логическое мышление [9].

Важнейшим фактором успешности педагогического процесса является адекватность представлений преподавателей о студентах различных регионов. А.И. Сурыгин подчеркивает, что «этнические стереотипы, которые складываются в процессе взаимо- 
действия преподавателей и учащихся, имеют большое значение для правильного выбора стиля педагогического общения» [10, с. 148-149]. Кроме того, для создания творческой атмосферы на уроке очень важен учет национально-культурного коммуникативного поведения студентов.

С.И. Шевелева также полагает, что знание и учет национально-культурных особенностей студентов и национально-педагогических традиций нужны для выбора соответствующего стиля педагогического общения, который будет способствовать нейтрализации культурного барьера, повышению скорости и качества обучения, т.е. интенсификации учебного процесса в целом: работа преподавателя должна быть направлена на интегрирование новых приемов обучения в привычные для китайцев, на последовательное и постепенное включение тех приемов, которые позволяют студентам осваивать иную манеру общения, например, споры и дискуссии [11, с. 117].

Чан Дин Лам, обращаясь к проблеме обучения китайских студентов за пределами КНР, полагает, что повышение эффективности обучения любого национального контингента относится к задачам этнопедагогики: «обучение людей различной этнической принадлежности требует учета закономерностей проявления их национальной психики, поскольку они влияют на восприятие и усвоение получаемых знаний» [12, с. 170].

Подобную точку зрения высказывает А.А. Щелокова: этнопсихологические факторы оказывают значительное влияние на эффективность процесса обучения иностранному языку: модель обучения РКИ сможет поддерживаться «факторами, положительно влияющими на процесс изучения языка, и нивелировать те факторы, которые отрицательно влияют на этот процесс» $[13$, с. 3$]$.

Этноориентированный подход к обучению китайских студентов русскому языку должен учитывать их ментальные особенности и привычные для учащихся методы и приемы обучения. Наиболее яркие национальные черты китайских студентов можно соотнести со стратегиями и тактиками преподавателя, способствующими оптимизации процесса обучения РКИ:

- представление о преподавателе как «двигателе успеха» - преподаватель должен задавать позитивный настрой на занятии;

- доминирование эмоциональности над рациональностью - преподаватель всегда должен проявлять сдержанность и такт;

- медлительность китайских студентов, склонность к обдумыванию - предпочтителен низкий темп обучения;

- зрительно-двигательный тип памяти у китайцев - преподаватель должен максимально использовать наглядность;

- высокий уровень мнемических способностей у китайских учащихся - необходимо привлекать тексты, предназначенные для заучивания (стихи, песни);

- привычка сначала знакомиться с грамматическим материалом дома, а затем тренироваться в его использовании на уроке - преподаватель должен дать новую тему как домашнее задание, а затем на занятии предложить большое количество тренировочных упражнений [6].

Таким образом, при разработке учебных программ, ориентированных на китайских студентов, в целях поддержания их мотивации к овладению русским языком и оптимизации процесса обучения в целом необходимо стремиться сделать процесс обучения не только результативным, но и максимально комфортным для обучающихся. Этому будет способствовать, во-первых, обязательная опора на развитые и устойчивые стороны этнопсихики и национальные черты китайских студентов (особенно в процессе адаптации к условиям обучения в России с целью смягчения отрицательных психологических процессов); во-вторых, «логичное и последовательное обучение новым приемам овладения языком и постепенное замещение учебно-познавательных приемов, характерных для системы китайского образования, применительно к методике русскому языку» [14, с. 37].

\section{Результаты и обсуждение}

Из сказанного следует, что процесс интенсификации обучения китайских студентов в России должен строиться с учетом большей доли психологической составляющей, ориентированной на национальнокультурные особенности учащихся. Однако А.А. Леонтьев подчеркивает, что в процессе обучения требуется взаимодействие индивидуально-психологических и коллективно-психологических качеств. В связи с этим, в понимании ученого, психологические основы интенсификации обучения иностранным языкам имеют трехуровневую структуру:

- дидактико-методический (ориентация на различные модальности восприятия и различные виды памяти, обеспечение мотивации овладения изучаемым языком);

- коллективно-психологический (создание условий для речевого взаимодействия);

- социально-психологический (усвоение требуемых знаний, навыков и умений каждым учащимся) [3, c. 293-294].

Применительно к грамматике, одной из основных трудностей разработки коммуникативно ориентированного курса всегда было (и есть) пропорциональное соотношение языковых и речевых упражнений и «временные» параметры их выполнения.

Коммуникативная методика обучения РКИ (в том числе и грамматике) нацелена на конструирование знания и его использование в непосредственном опыте, на операции анализа и синтеза, на развитие критического и творческого мышления, что, как уже неоднократно отмечалось, не соответствует когнитивным особенностям китайских учащихся. Так, иероглифическая система китайского языка наложила отпечаток на способ мышления данного контингента учащихся: китайские учащиеся привыкли мыслить образами, и точного соответствия между русским и китайским языковым мышлением не существует [6]. На основе данных анализа грамматических ошибок Е.В. Беляева отмечает, что «две языковые системы (русского языка и китайского) как две когнитивные системы мировидения представляют различный набор смыслов, который в русском языке закодирован в грамматических категориях, а в китайском выражается лексически» [4, с. 12]. Это означает, что на этапах введения, закрепления и контроля нового грамматического явления требуется поиск некоего компромисса: содержание, средства, формы, методы обучения должны гармонично соотноситься как с «внешними условиями», так и с особенностями учащихся, обеспечивая одновременно и интенсивность, 
и результативность, и мотивацию к дальнейшему овладению РКИ.

Опираясь на описанные выше лингвометодические традиции Китая и на «сильные» и «слабые» стороны этнопсихологического портрета китайского студента как факторы, положительно и отрицательно влияющие на реализацию основных принципов обучения, нами разработаны рекомендации по обучению русской грамматике с максимальным учетом когнитивнопсихологических особенностей китайских студентов.

Принимая во внимание предрасположенность китайцев к длительному осмыслению материала, важно, чтобы урок по грамматике строился с обязательным и последовательным соблюдением следующих стадий формирования грамматического навыка: 1) восприятие, 2) имитация, 3) подстановка, 4) трансформация, 5) репродукция, 6) комбинирование [15, с. 403-409].

Перечисленные стадии выделены по критерию «действия учащегося» с усваиваемым речевым материалом. Учитывая, что китайцам свойственно в большей степени аккумулирование знаний, а не их конструирование и логическое осмысление, следует добавить к перечисленным выше стадиям еще одну «вводную»- предварительное знакомство с правилом.

Как известно, существует два способа введения грамматического материала - индуктивный и дедуктивный. Относительно китайцев исследователи единогласно выступают за дедуктивный способ, при этом как способы оформления грамматической модели, так и демонстрация ее функций в речи должны быть абсолютно понятны и сопровождаться разными видами наглядности. Принципы доступности и наглядности опираются на такую особенность китайцев, как склонность к простым логическим конструкциям: «китаец, как правило, отдает предпочтение простым интеллектуальным построениям как наиболее доступным и рациональным для запоминания» [13, c. 1]. При этом прочность усвоения правила будет обеспечиваться способностью китайцев заучивать большой объем информации наизусть.

Трудолюбие китайцев, согласно конфуцианской философии, может компенсировать недостаток способностей. Зная о такой особенности китайцев, как «подчинение бесконечного разнообразия привычному стандарту» [16, с. 84], при демонстрации нового грамматического явления преподаватель должен использовать принцип квантования правила [15, с. 412]. Преподнесение правила «маленькими порциями» с использованием графической и предметной наглядности, сопровождаемое «памятками» или «грамматическими фокусами» и четкими инструкциями соответствует конкретно-символическому мышлению китайцев. Последующая отработка на большом количестве речевых ситуаций в ходе выполнения условноречевых упражнений в наибольшей степени обеспечивает частотность употребления, необходимую китайцам для автоматизации грамматического навыка.

Правильный выбор грамматической формы для оформления высказывания зависит и от того, насколько усвоено говорящим грамматическое значение этой формы. Иначе говоря, для активного употребления грамматического явления в речи важны и оформление, и ситуация, в которой функционирует данная форма.
Е.С. Овсий отмечает, что китайцам, прежде чем устанавливать коммуникацию, «необходимо понимать всю структуру иностранного языка, который они изучают» $[17$, с. 78$]$. С этим связана такая психологическая особенность китайских учащихся, как «сохранение лица», проявляющаяся в боязни совершить ошибку, нежелании на занятии инициировать общение (например, с преподавателем) и предпочтении пассивных методов обучения, центрированных на работе по учебнику. Однако Т.М. Балыхина и Чжао Юйцзян характеризуют образ мышления китайца как практический [16, с. 80]. Более того, Ван Лися подчеркивает, что китайская языковая личность проактивна, т.е. способна «адаптироваться в любой среде, пользуясь как экстравертивными, так и интровертивными стратегиями общения (в том числе и учебного общения)» и легко преодолевать трудности учебного процесса $[18$, с. 6]. Таким образом, необходимо обеспечить не только прочное знание грамматической формы и значения демонстрируемой модели («накопление знаний»), но и добиться ее активного употребления в речи. Следует нацелить китайских обучающихся прежде всего «на установление коммуникации и через нее учить язык», при этом на первом месте должно быть «как сказать?», а не «чем сказать?» [17, с. 78]. Осуществляется это благодаря повышению интереса к используемому на занятии материалу. Отрабатывать новое грамматическое явление следует не многократным повторением, а «путём направленного использования материала в непосредственном опыте общения» [9].

Мотивировать китайцев к изучению русской грамматики можно с помощью активного использования наглядности, т.к. у данного контингента развит зрительный канал восприятия информации. А.К. Новикова рекомендует интенсивное применение видеоматериалов, поскольку «яркие зрительные образы являются эффективным источником как ознакомления китайских учащихся с реалиями российской жизни, так и облегчения построения ими собственного высказывания с опорой на видео как источник восприятия» [19, с. 162]. Так, на стадии восприятия грамматического материала эффективнее всего использовать короткие аутентичные видеофрагменты с обязательным предварительным снятием лексических трудностей с использованием словаря (предпочтения китайцев), после чего можно организовать беседу в вопросно-ответной форме, являющейся привычной для китайцев и настраивающей на сюжет.

При помощи видеоматериалов осуществляется демонстрация значения грамматической модели в реальных условиях употребления носителями изучаемого языка, что способствует формированию динамического стереотипа. Кроме того, включается пространственно-образное мышление учащихся, благодаря чему при просмотре видео складывается целостный образ грамматической конструкции «в действии», сопоставимый с тем, что происходит при чтении китайских иероглифов.

Китайские учащиеся чувствуют себя «некомфортно, если часто меняется тема разговора», поэтому работу по усвоению грамматических структур на начальном этапе лучше строить на небольших микротекстах монологического характера и в «монологическом общении» $[18$, с. 10]. На стадии имитации, 
когда осознается функциональная сторона модели и запоминается ее форма, в китайской аудитории можно предложить, например, скрипт просмотренного видеосюжета, который будет являться одновременно и примером работы с аутентичным текстом (формирование контекстно-зависимых стратегий осмысления явлений текста). При этом проверка выполненных заданий сводится к повторному просмотру видеосюжета, т.е. подкрепляется опорой на зрительную и зрительно-моторную память, что обеспечивает связь слухового и рече-моторного образов грамматической модели.

На стадии подстановки, где начинается формирование операции оформления, зарождается осознание обобщенности модели [15, с. 407] и увеличивается способность к репродукции на основе аналогии, важно учитывать следующее:

1) в целях поддержания мотивации китайских учащихся следует использовать речевые ситуации, моделирующие естественную коммуникацию и отобранные с учетом интересов китайцев;

2) поскольку китайские учащиеся привыкли действовать по образцу (по аналогии), организация учебной деятельности должна быть строго регламентирована и сопровождаться четкими указаниями и инструкциями по применению;

3) если запоминание идет главным образом через зрительное восприятие, то упражнения и задания необходимо дополнять зрительной аутентичной наглядностью (реальные фото, объявления, реклама и т.п.).

Чтобы ускорить переход от понимания грамматической конструкции к ее употреблению в речи, на стадии репродукции рекомендуется ориентироваться на предприимчивость и азартность китайцев. Соревновательный элемент грамматических игр поможет учащимся перейти от сознательного выполнения операций к автоматизации грамматического навыка.

В игре правилом выступает образец, а то, что написано/нарисовано на карточках, кубиках и т.п., выполняет функцию ориентировки, и это как нельзя лучше согласовывается со зрительным типом памяти китайцев. Атмосфера игры «на руку» эмоциональному началу китайцев, поскольку снимает психологический барьер и значительно уменьшает напряжение, препятствующее свободному говорению.

На стадии комбинирования предполагается работа в группе, учитывающая такую когнитивно-психологическую особенность, как коллективизм. На этой стадии происходит управляемое комбинирование действий, усвоенных на предыдущих стадиях, в результате вырабатывается устойчивость грамматического навыка. Работа, связанная с поиском информации в интернете или с использованием драматизации и песен, предполагает решение именно речевой задачи, отвечает любознательности китайцев и создает необходимую речевую мотивированность высказывания.

Для контроля уровня владения изученным материалом может использоваться тест множественного выбора.

Домашнее задание в форме речевой задачи преследует цель закрепить грамматические навыки, имеет обязательный выход в реальную языковую среду (например, вопросы виртуальному русскому другу) и способствует необходимому для китайского студента повторению и осмыслению пройденного материала.

\section{Выводы}

Новизна предпринятого исследования заключается в попытке разрешить противоречие между потребностью в формировании правильных устойчивых грамматических навыков у китайских учащихся в процессе обучения русскому языку и недостаточным вниманием преподавателей-русистов к когнитивно-психологическим особенностям данного контингента учащихся.

При обучении китайских студентов русской грамматике следует организовывать работу над грамматическим материалом и учебную деятельность таким образом, чтобы, ориентируясь на стратегии усвоения языкового и речевого материала, оптимальные для китайской аудитории, создать условия, способствующие вовлечению учащихся в процесс общения на русском языке.

Это оказывается возможным при соблюдении следующих принципов организации и подачи материала:

- на этапе предъявления и ознакомления с грамматической темой следует опираться на такие особенности китайцев, как хорошая память и способность запоминать большой объем информации, а также конкретно-символическое мышление и склонность к простым логическим построениям. Предпочтителен дедуктивный способ введения нового материала с использованием графической и предметной наглядности. Грамматическое правило необходимо предъявлять квантами, сопровождать четкими инструкциями и разными типами наглядности, а для активизации усвоенного материала создавать большое количество разнообразных аутентичных ситуаций общения, способных устанавливать прочные связи между формой и функцией;

- обязательное использование аутентичных аудиои видеоматериалов, аутентичных печатных текстов (реклама, объявления, вывески) не только на этапе восприятия нового грамматического материала, но и на этапе закрепления и активизации грамматических конструкций обусловлено зрительным типом памяти китайцев. С помощью таких материалов можно создать на уроке условия реальной языковой среды, что соответствует практическому мышлению китайцев и, следовательно, повышает мотивацию студентов к употреблению изучаемого грамматического явления в активной речевой деятельности. Задания на поиск информации в интернете помогает развивать их самостоятельность;

- систематическая практика общения, направленная на проверку усвоения правил образования грамматической формы и на автоматизацию навыков выбора ее функциональных значений, должна быть организована на основе грамматических игр, которые выступают в качестве условно-речевых упражнений. Благодаря этому можно добиться устойчивости грамматического навыка, поскольку повторение речевых действий с закрепляемыми структурами обеспечивает их воспроизводимость в разных условиях. С другой стороны, игры учитывают такие психологические особенности китайцев, как предприимчивость, готовность к конкуренции и азартность.

Отметим также, что обучение китайских студентов русской грамматике, построенное с учетом их когнитивно-психологических особенностей, не только будет способствовать формированию прочных грамматических навыков, но и станет надежной базой для развития умений спонтанного общения на русском языке. 


\section{Список литературы:}

1. Федотова Н.Л. Методика преподавания русского языка как иностранного (практический курс). 2-е изд. СПб.: Златоуст, 2016. 192 с.

2. Зимняя И.А. Психология обучения неродному языку. М.: Русский язык, 1989. 219 с.

3. Леонтьев А.А. Психологические основы наглядности в учебнике иностранного языка // Язык и речевая деятельность в общей и педагогической психологии: Избранные психологические труды. М.: Московский психолого-социальный институт; Воронеж: НПО «МОДЭК», 2001. С. 282-302.

4. Беляева Е.В. Когнитивные механизмы возникновения речевых ошибок при усвоении русского языка в иноязычной аудитории (на материале ошибок китайских студентов): автореф. дис. ... канд. пед. наук. Омск, 2004. 25 с.

5. Гассиева И.И., Молочко Н.В., Мельникова Т.В. Из опыта обучения китайских студентов в вузе. Евразия: межкультурное взаимодействие в экономическом и образовательном пространстве: мат-лы междунар. науч.-практ. конф., Минск, 28 января 2016 года / редкол.: Н.В. Попок (гл. ред.) [и др.]. Мн.: БГЭУ, 2017. С. 161-165.

6. Вакула Е.А., Колесникова В.В., Можаева Е.Ю. Особенности преподавания русского языка как иностранного китайским слушателям на начальном этапе обучения [Электронный ресурс] // Современные проблемы науки и образования. 2018. № 4. - http:// science-education.ru/ru/article/view?id=27790.

7. Балыхина Т.М., Чжао Юйцзян. Какие они, китайцы? Этнометодические аспекты обучения китайцев русскому языку // Высшее образование сегодня. 2009. № 5. C. 16-22.

8. Fedotova N.L., Solovyeva E.B., Vtorov V.B., Yun L.G. Implementing Sino-Russian educational programs for the training of Chinese engineers // Integration Education. 2019. T. 23, № 2. P. 164-181. DOI: 10.15507/19919468.095.023.201902.164-181.

9. Кошелева Е.Ю., Пак И.Я., Чернобыльски Э. Этнопсихологические особенности модели обучения китайских студентов [Электронный ресурс] // Совре- менные проблемы науки и образования. 2013. № 2. http://science-education.ru/ru/article/view?id=8695.

10. Сурыгин А.И. Основы теории обучения на неродном для учащихся языке. СПб.: Златоуст, 2000. $225 \mathrm{c}$.

11. Шевелева С.И. Учет национальных особенностей студентов из стран азиатско-тихоокеанского региона при обучении русскому языку как иностранному // Вестник Томского государственного педагогического ун-та. 2010. Вып. 12 (102). С. 115-118.

12. Чан Дин Лам. Обучение китайских студентов за пределами Китая: проблемы и решение // Успехи современного естествознания. 2014. № 5-1. С. 170-173.

13. Щелокова А.А. Реализация этнопсихологического принципа обучения русскому языку как иностранному // Научно-методический электронный журнал «Концепт». 2017. № V9. C. 88-94.

14. Большакова Н.Г., Низкошапкина О.В. Этноориентированная методика обучения китайских учащихся самостоятельному чтению // Вестник РУДН. Серия Вопросы образования: языки и специальность. 2015. № 4. С. 36-40.

15. Пассов Е.И., Кузовлева Н.Е. Урок иностранного языка. Ростов-на-Дону: Феникс; М.: Глосса-Пресс, $2010.640 \mathrm{c}$.

16. Балыхина Т.М., Чжао Юйцзян. От методики к этнометодике. Обучение китайцев русскому языку: проблемы и пути их преодоления. М.: РУДН, 2010. 344 с.

17. Овсий Е.С. Учет этнопсихологических особенностей китайских обучающихся при использовании коммуникативного подхода к обучению русскому языку как иностранному // Балтийский гуманитарный журнал. 2019. Т. 8, № 2 (27). С. 77-79.

18. Ван Лися. Обучение китайских студентов русскому языку с учетом национальной языковой личности (начальный этап обучения) // Интерактивная наука. 2017. C. 1-12. DOI: 10.21661/r-464039.

19. Новикова А.К. К вопросу о видеоматериалах на уроке РКИ в китайской аудитории // Вестник РУДН. Серия: Вопросы образования: языки и специальность. 2013. № 4. С. 159-164.

\section{TAKING INTO ACCOUNT CHINESE STUDENTS' COGNITIVE AND PSYCHOLOGICAL CHARACTERISTICS WHILE TEACHING RUSSIAN GRAMMAR} (C) 2020

Sun Yu, postgraduate student of Russian as a Foreign Language and Teaching Methods Department Saint Petersburg State University (Saint Petersburg, Russian Federation)

Abstract. This paper aims to discuss the problem of nationally oriented teaching of Russian grammar to Chinese students. The author analyzes the works that are devoted to the study of Chinese students' cognitive and psychological characteristics. The analysis revealed specific learning strategies that Chinese students use when learning a foreign language. When training a mono-ethnic group, the national-oriented approach is considered optimal. To implement this approach, a comparative analysis of systems of contacting languages is necessary to determine the zones of interlanguage and intralanguage interferences. The most important factor in the effectiveness of the educational process is the adequacy of the teachers' ideas about students from different regions. The author concludes that in order to maintain motivation for mastering the Russian language and optimize the learning process as a whole when developing curricula and class books for Chinese students, it is necessary to strive to make the learning process not only effective, but also as comfortable as possible for students. Taking into account Chinese students' cognitive and psychological characteristics will not only contribute to the development of strong grammar skills, but will also ensure the development of oral speech skills in Russian. The paper provides recommendations for intensifying the process of teaching Russian grammar to Chinese students. The following research methods were used: a comparative analysis, an analysis and a synthesis.

Keywords: foreign language speech activity; teaching; grammar; ethnocultural aspect; cognitive and psychological characteristics; grammar skill; grammar exercises; ways of presenting grammatical material; Russian as foreign language (RFL); Chinese students. 